\title{
Effects of cement-curing mode and light-curing unit on the bond durability of ceramic cemented to dentin
}

\section{Sheila Pestana Passos ${ }^{(a)}$ Rodrigo Othávio Assunção Souza(b) \\ Silvia Masae Araújo Michida(c) \\ Sandra Costa Zamboni(d) \\ Simone Helena Gonçalves de Oliveira $^{(e)}$}

(a) Department of Dentistry, University of Alberta, Edmonton, AB, Canada.

(b) Department of Restorative Dentistry, Univ Federal da Paraíba - UFPB, João Pessoa, PB, Brazil.

(c)Department of Prosthodontics, Faculdade Ingá - Uningá, Maringá, PR, Brazil.

(d) Department of Dental Materials and Prosthodontics, School of Dentistry, Univ Estadual Paulista - Unesp, São José dos Campos, SP, Brazil.

(e) Department of Bioscience and Oral Diagnosis, School of Dentistry, Univ Estadual Paulista - Unesp, São José dos Campos, SP, Brazil.

Declaration of Interests: The authors certify that they have no commercial or associative interest that represents a conflict of interest in connection with the manuscript.

Corresponding Author:

Rodrigo Othávio Assunção Souza

E-mail: roasouza@yahoo.com.br

Submitted: Sep 14, 2012

Accepted for publication: Dec 11, 2012

Last revision: Dec 21, 2012

\begin{abstract}
The aim of this study was to evaluate the effects of different light-curing units and resin cement curing types on the bond durability of a feldspathic ceramic bonded to dentin. The crowns of 40 human molars were sectioned, exposing the dentin. Forty ceramic blocks of VITA VM7 were produced according to the manufacturer's recommendations. The ceramic surface was etched with $10 \%$ hydrofluoric acid/60s and silanized. The dentin was treated with $37 \%$ phosphoric acid $/ 15 \mathrm{~s}$, and the adhesive was applied. The ceramic blocks were divided and cemented to dentin according to resin cement/RC curing type (dual- and photocured), light-curing unit (halogen light/ QTH and LED), and storage conditions (dry and storage/150 days $+12,000$ cycles/thermocycling). All blocks were stored in distilled water $\left(37^{\circ} \mathrm{C} / 24 \mathrm{~h}\right)$ and sectioned $(\mathrm{n}=10)$ : G1 - QTH + RC Photo, G2 - QTH + RC Dual, G3 - LED + RC Photo, G4 - LED + RC Dual. Groups G5, G6, G7, and G8 were obtained exactly as G1 through G4, respectively, and then stored and thermocycled. Microtensile bond strength tests were performed (EMIC), and data were statistically analyzed by ANOVA and Tukey's test $(5 \%)$. The bond strength values $(\mathrm{MPa})$ were: G1 - $12.95(6.40)^{\mathrm{ab}} ; \mathrm{G} 2$ - $12.02(4.59)^{\mathrm{ab}} ; \mathrm{G} 3$ $13.09(5.62)^{\mathrm{ab}} ; \mathrm{G} 4-15.96(6.32)^{\mathrm{a}} ; \mathrm{G} 5-6.22(5.90)^{\mathrm{c}} ; \mathrm{G} 6-9.48(5.99)^{\mathrm{bc}}$; G7 - $12.78(11.30)^{\mathrm{ab}}$; and G8 - $8.34(5.98)^{\mathrm{bc}}$. The same superscript letters indicate no significant differences. Different light-curing units affected the bond strength between ceramic cemented to dentin when the photocured cement was used, and only after aging (LED > QTH). There was no difference between the effects of dual- and photo-cured resin-luting agents on the microtensile bond strength of the cement used in this study.
\end{abstract}

Descriptors: Resin Cements; Ceramics; Dentin.

\section{Introduction}

In association with the development of ceramic materials, resin cements also demonstrate increased improvement in their chemical and mechanical characteristics. These cements can be divided according to the type of activation:

$$
\begin{aligned}
& \text { - self-, } \\
& \text { - light-, or } \\
& \text { - dual-curing. }
\end{aligned}
$$

The dual resin cement presents reagents of both forms of polymeriza- 
tion. ${ }^{1}$ The chemical component ensures adequate polymerization in the areas of the cement that do not receive sufficient light to initiate polymerization. ${ }^{2}$ Many studies have reported that the resin cements with dual polymerization are extremely dependent on photoactivation, since chemical polymerization itself is insufficient to complete the polymerization of these cements. ${ }^{3}$

The degree of conversion (DC) depends on the energy supplied during composite polymerization, characterized as the product of luminous intensity and time of exposure. ${ }^{4,5}$ Reduced microhardness can be synonymous with incomplete resin cement polymerization, causing a reduction in the mechanical properties of the cement, increasing water absorption $^{6}$ and favoring microinfiltration. ${ }^{7}$ Moreover, unpolymerized molecules can be leached from the material, causing inflammation. ${ }^{8}$ Therefore, it is important to optimize the photoactivation of resin cements to improve the clinical performance of these materials. Fan et al. ${ }^{9}$ affirmed that the periods of light exposure recommended by resin manufacturers are not always adjusted to provide complete polymerization.

The clinical performance of feldspathic ceramic restorations is directly related to the cementing procedure, since it involves the union between different substrates (ceramic and dental structure). ${ }^{10}$ For this adhesive process, the dental and ceramic surfaces must be adequately conditioned. Additionally, there must be adequate polymerization of the resin cement agent, since it is essential in preventing microleakage and allowing for greater longevity of the restoration.

Thus, the objective of the current study was to verify the effects of different light-curing units and different types of polymerization of the cement agent on the bond durability of a feldspathic ceramic cemented to dentin. The appropriate photoactivation of the resin cement is considered an essential factor for adequate bond strength at the ceramiccement-dentin interface, as well as for optimization of the physical properties. ${ }^{11}$ Our study hypotheses were that:

- (1) different light-curing units influence the bond strength of ceramic cemented to dentin,

- (2) dual-cure resin cement improves bond strength, and
- (3) storage affects bond strength values.

\section{Methodology}

This study was approved by the Research Ethics Committee of São Paulo State University, São José dos Campos, Brazil.

Forty non-carious human molars were extracted for periodontal or orthodontic reasons, and stored in distilled water. The crowns were transversely sectioned with a diamond saw at low speed and with intense water-cooling, exposing the mid-coronal dentin. The distance between the cementoenamel junction and the flat dentin surface was kept to a similar depth for all specimens. Dentin surfaces were visually inspected for the absence of enamel. We created a standardized smear layer by wet-grinding the dentin surface flat with 600-grit silicon carbide paper for $60 \mathrm{~s}$ (Labpol 8-12, Extec, Enfield, USA).

Forty ceramic blocks $(6.4 \times 6.4 \times 2.5 \mathrm{~mm})$ of VITA VM7 (Base Dentin 2M3, Vita Zahnfabrik, Bad Säckingen, Germany, \#31570, liquid 17501) were produced. The cementation surface of each ceramic block was leveled and polished with silicon carbide papers in sequence (600-, 800-, and 1200 -grit) under water-cooling.

All ceramic blocks were ultrasonically cleaned for $5 \mathrm{~min}$ in distilled water. The cementation surfaces were etched with $10 \%$ hydrofluoric acid gel (Dentsply, Petrópolis, Brazil, \#L806765) for $60 \mathrm{~s}$, rinsed with water, and air-dried. The ceramics were ultrasonically cleaned in distilled water for $5 \mathrm{~min}$. Then, the silane was applied (Monobond-S, Ivoclar Vivadent, Schaan, Liechtenstein, \#H24764) and allowed to sit for $5 \mathrm{~min}$.

The coronal dentin was treated with a multistep total-etch adhesive system (Excite DSC, Ivoclar Vivadent, Schaan, Liechtenstein, \#H23024). The dentin surface was air-dried and etched with $37 \%$ phosphoric acid (Dentsply, Petrópolis, Brazil, \#040707) for $15 \mathrm{~s}$ and washed, and then the excess water was removed with absorbent paper. Two layers of the adhesive system were applied to the coronal dentin. The specimens were gently air-dried and light-cured for $20 \mathrm{~s}$, by means of a QTH (XL 3000, 3M/ESPE, St. Paul, USA; 
light intensity: $600 \mathrm{~mW} / \mathrm{cm}^{2}$ ) or a LED (SmartLite PS/ Dentsply, Petrópolis, Brazil, light intensity: $950 \mathrm{~mW} / \mathrm{cm}^{2}$ ).

The 40 ceramic blocks were randomly divided into four groups $(n=10)$ based on the factors "light-curing units" (QTH and LED) and "resin cement" (Variolink II photo- and dualcured, Ivoclar Vivadent, Schaan, Liechtenstein; Base, G24884; Catalyst, J09824). The cement was placed on the treated ceramic and coronal dentin surfaces, following the manufacturer's instructions. Each ceramic block was placed on the dentin surface under a load of $750 \mathrm{~g}$ for $5 \mathrm{~min}$. The resin cement was light-activated by the light-curing units QTH or LED for $40 \mathrm{~s}$, according to the experimental group assignment. The specimens from all groups were stored in distilled water for $24 \mathrm{~h}$ at $37^{\circ} \mathrm{C}$ prior to microtensile bond strength (MTBS) testing.

The specimens were sectioned by means of a diamond disc, under water cooling (LabCut 1010, Extec, Enfield, USA). Approximately 10 specimens were obtained from each block. The beam specimens had non-machined (non-trimmed) bonding areas measuring approximately $1.0 \pm 0.1 \mathrm{~mm}^{2}$ and a length of $6 \mathrm{~mm}$. The specimens were randomly divided into 2 testing conditions. In the dry condition (Dry), specimens were immediately subjected to MTBS after being sectioned, while in the aged condition, specimens were subjected to thermocycling (TC: 12,000 cycles; $5^{\circ} \mathrm{C}-55^{\circ} \mathrm{C}$ ) (Nova Etica, São Paulo, Brazil) and storage (150 days) in distilled water at $37^{\circ} \mathrm{C}$, and then tested.

Therefore, 8 groups were obtained $(\mathrm{n}=10)$ :

- G1 - QTH + dual-cured resin cement + Dry;

- G2 - QTH + photo-cured resin cement + Dry;

- G3 - LED + dual-cured resin cement + Dry;

- G4 - LED + photo-cured resin cement + Dry;

- G5 - QTH + dual-cured resin cement + TC;

- G6 - QTH + photo-cured resin cement + TC;

- G7 - LED + dual-cured resin cement + TC; and

- G8 - LED + photo-cured resin cement + TC.

The MTBS was performed in a universal testing machine (EMIC DL-1000, EMIC, São José dos Pinhais, Brazil). The specimens were analyzed un- der an optical microscope (Mitutoyo, Measuring Microscope MFA - Series 5051H, Suzhavo, Japan). The failure types were classified according to the following scores: ${ }^{12}$

- Score A, adhesive failure along the interfacial region between the dentin and resin cement;

- Score B, cohesive failure in the dentin;

- Score C, cohesive failure in the resin cement; and

- Score D, mixture of adhesive failure and cohesive fracture of the dentin or resin cement.

In addition, some representative specimens from each group were analyzed under SEM (LEO1450VP/LEO-Zeiss, Oberkochen, Germany).

The MTBS data were analyzed by three-way analysis of variance (ANOVA) and Tukey's multiple-comparison tests (5\%). P-values less than 0.05 were considered to be statistically significant in all tests.

\section{Results}

Three-way ANOVA revealed that the MTBS was significantly affected by light-curing units $(\mathrm{p}=0.0037<0.05)$ and storage conditions $(\mathrm{p}=0.0001<0.05)$. The interaction among the light-curing unit, resin cement, and storage factors was statistically significant $(\mathrm{p}=0.0030)$.

Table 1 and Figure 1 present the MTBS results for the experimental groups. When the storage was

Table 1 - Mean ( \pm SD) bond strength values (MPa) for lightcuring units, resin cement, and storage combinations [*The same superscript letters indicate no significant differences (Tukey's test, $\alpha=0.05)$.]

\begin{tabular}{c|c}
\hline Experimental groups & Mean (SD) \\
\hline Group 1 & $12.95 \pm 6.40^{\mathrm{ab}}$ \\
\hline Group 2 & $12.02 \pm 4.59^{\mathrm{ab}}$ \\
\hline Group 3 & $13.09 \pm 5.62^{\mathrm{ab}}$ \\
\hline Group 4 & $15.96 \pm 6.32^{\mathrm{a}}$ \\
\hline Group 5 & $6.22 \pm 5.90^{\mathrm{c}}$ \\
\hline Group 6 & $9.48 \pm 5.99^{\mathrm{bc}}$ \\
\hline Group 7 & $12.78 \pm 11.30^{\mathrm{ab}}$ \\
\hline Group 8 & $8.34 \pm 5.98^{\mathrm{bc}}$ \\
\hline Mean (SD) & $4.4 \pm 1.9$ \\
\hline
\end{tabular}

* $\mathrm{Gr} 1$ to $\mathrm{Gr} 4$ = without thermocycling; $\mathrm{Gr} 5$ to $\mathrm{Gr} 8$ = with thermocycling. 

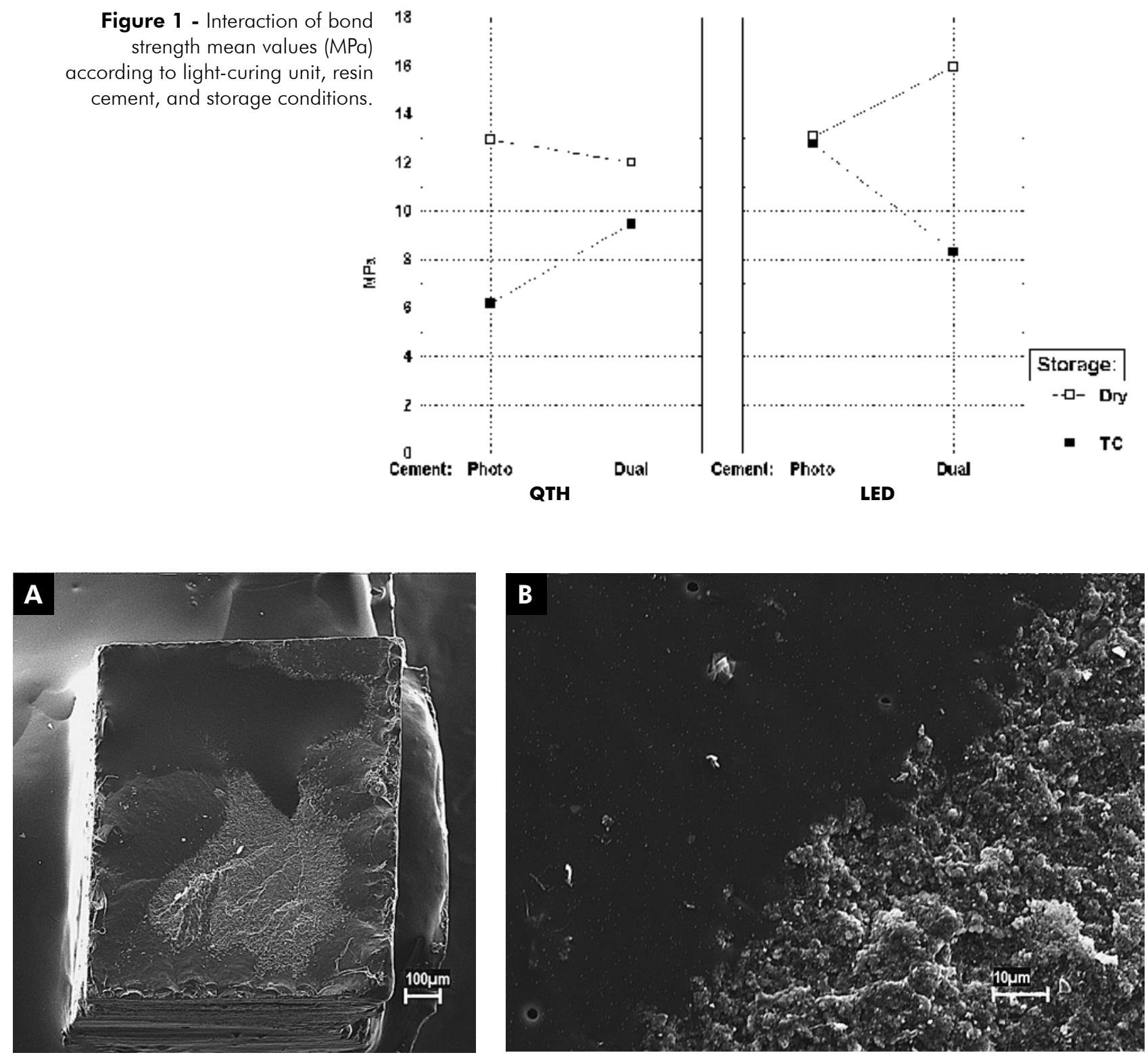

Figure 2 - Representative micrographs of a mixture failure of a specimen from G4 (A, 64× and B, 1000x) after MTBS testing.

analyzed, the dry condition presented values significantly higher when compared with the thermocycling condition in groups G1/G5 and G4/G8. Similar results were found when the light-curing units were compared, except for G5/G7. In contrast, when the resin cement was analyzed, the values of photoand dual-cured cement were similar.

Regarding fracture analysis, most specimens presented mixed failures. No scores of $\mathrm{A}$ and $\mathrm{C}$ were observed. A representative micrograph of a mixed fracture is presented in Figures $2 \mathrm{~A}$ and $2 \mathrm{~B}$.

\section{Discussion}

Different factors, including the type and chemical composition of the resin matrix (filler type or filler load), determine the mechanical properties of resin-luting agents, ${ }^{11}$ and also lead to variations in bond strength to dentin. Therefore, only one dualpolymerized resin-luting agent was chosen for the present study, and it was used with a catalyst (dual polymerization mode) to eliminate the previously mentioned material-dependent properties. Variation in tubule density at different dentin depths 
is another significant factor that influences bond strength. ${ }^{13}$

The first and third hypotheses were partially accepted:

- (1) different light-curing units influence the bond strength of the ceramic cemented to dentin only for the photo-cured resin cement after aging, and

- (3) storage did not affect the bond strength values of all groups.

The second hypothesis was not validated: There was no difference between the effects of photoand dual-cured resin cement on bond strength.

When one considers the direct relationship between polymerization of the resin-luting agent and its bond strength to dentin, the risk of debonding is higher immediately following cementation, because the cement has not yet reached the highest degree of polymerization. If some factor prevents the light from reaching the cement layer, thereby causing insufficient polymerization, then areas of cohesive failure in the resin-luting agent should be detected in SEM analysis. In the present study, the SEM observations revealed mixed failures (Figures 2A, 2B). Hofmann et al. ${ }^{14}$ verified that flexural strength, modulus, and hardness of self-cured Variolink II reached $68.9 \%, 59.2 \%$, and $91.1 \%$, respectively, of the corresponding values obtained by dual-curing with direct irradiation.

Adequate curing of resin-luting materials may also be a problem under ceramic restorations, especially when these resins are used without a catalyst. ${ }^{14,15}$ In previous studies, the use of a selfcuring catalyst resulted in a higher degree of polymerization when compared with that achieved by light polymerization alone. ${ }^{7}$ However, in the present study, no difference was found between the resin cement curing modes evaluated in terms of bond strength. El-Mowafy and Rubo ${ }^{16}$ showed that dual-cured resin cements reached an adequate $\mathrm{DC}$, even in areas that are less accessible to the curing light, emphasizing the importance of the self-curing catalyst. In contrast, chemical curing alone of Variolink II produced lower values of surface hardness when compared with those achieved by light- or dual-curing. ${ }^{11,16}$ Photo-curing of dual-cured resin-luting agents provides an initial fixation for restorations, with chemical-curing responsible for the final bonding. ${ }^{17}$ In contrast, the results of the present study showed that the use of a catalyst of the resin cement studied produced no difference on the bond strength when compared with the bond strengths obtained with light-curing.

Another consideration in relation to the degree of polymerization of resin-luting agents is the intensity of the light-curing unit. In several studies, the curing efficacy of halogen and LED curing units has been compared..$^{7,14,18-24}$ LED curing units provide efficient energy, with a peak length of about $470 \mathrm{~nm}$ required by the photo-initiator, camphorquinone. ${ }^{25}$ It has generally been found that light intensity, not the light-curing unit itself, was the decisive factor determining the DC and resulting in the expected physical and mechanical properties of resin composites. ${ }^{5}$ The ISOrecommended intensity for polymerization lights is $300 \mathrm{~mW} / \mathrm{cm}^{2}$, and the standard requirement for depth of polymerization is $1.5 \mathrm{~mm} .{ }^{9}$ Light intensities of $600 \mathrm{~mW} / \mathrm{cm}^{2}$ and $950 \mathrm{~mW} / \mathrm{cm}^{2}$ were used for polymerization in the current study. Polymerization of light-polymerized resin-luting agents for all-ceramic restorations may be incomplete when low-output polymerization units are used..$^{15}$ For this reason, a high-intensity light-curing unit and longer polymerization times may directly affect bond strength values. Feng et al. ${ }^{26}$ suggested at least doubling the photocuring time recommended by the manufacturers.

The light-curing units under investigation presented similar results except for the photo-curing resin cement groups after aging. It can be initially assumed that differences between the activation modes occurred because of differences in the mechanical strength of the resin cements. In fact, previous studies have shown that Variolink II presents a lower DC and hardness in the self-cure mode when compared with the dual-cure mode.,11 In other studies, ${ }^{2,16}$ it was reported that Variolink II has a relatively weak chemical polymerizing component and relies mainly on its light-polymerizing capability. 
The present study examined the early strength and durability of the Vita VM7 ceramic sample bonded to dentin. An important factor related to water sorption of resin-based composite materials would appear to be the degree of polymerization. Water sorption itself may not cause significant problems, but if it is associated with incomplete polymerization, the long-term success of a restoration may be compromised. The results of the present study demonstrated that thermocycling $(12,000$ cycles) and 150 days of storage did not result in decreased MTBS values in all groups. These findings are supported by those of other studies. ${ }^{27}$ Another study ${ }^{21}$ indicated that the type of surface-conditioning agent, rather than the type of resin-luting agent, predominantly influenced the bond strength to ceramic.

Numerous factors-such as optical properties of the ceramic material, ${ }^{28}$ the types and chemical

\section{References}

1. Dong CC, McComb D, Anderson JD, Tam LE. Effect of mode polymerization of bonding agent on shear bond strength of autocured resin composite luting cements. J Can Dent Assoc. 2003 Apr;69(4):229-34.

2. Caughman WF, Chan DC, Rueggeberg FA. Curing potential of dual-polymerizable resin cements in simulated clinical situations. J Prosthet Dent. 2001 Jul;86(1):101-6.

3. Witzel MF, Braga RR, Singer JM, Azevedo CL. Bond strength between polymer resin-based cement and porcelain-dentin surfaces: influence of polymerization mode and early cyclic loading. Int J Prosthodont. 2003 Mar-Apr;16(2):145-9.

4. Elekdag-Turk S, Sarac YS, Turk T, Sarac D. The effect of a light-emitting diode on shear bond strength of ceramic brackets bonded to feldspathic porcelain with different curing times. Eur J Orthod. 2007 Jun;29(3):299-303.

5. Rueggeberg FA, Caughman WF, Curtis JW Jr, Davis HC. A predictive model for the polymerization of photo-activated resin composites. Int J Prosthodont. 1994 Mar-Apr;7(2):159-66.

6. Uctasli S, Hasanreisoglu U, Wilson HJ. The attenuation of radiation by porcelain and its effect on polymerization of resin cements. J Oral Rehabil. 1994 Sep;21(5):565-75.

7. Jung H, Friedl KH, Hiller KA, Furch H, Bernhart S, Schmalz G. Polymerization efficiency of different photocuring units through ceramic discs. Oper Dent. 2006 Jan-Feb;31(1):68-77.

8. DeWald JP, Ferracane JL. A comparison of four modes of evaluating depth of cure of light-activated composites. J Dent Res. 1987 Mar;66(3):727-30. compositions of the resin-luting agents, ${ }^{29}$ and the use of different cements ${ }^{30}$ and ceramic shadesmay influence the polymerization degree of resinluting agents. Therefore, it was not possible to include all of these variables in the same in vitro study. However, according to the results of this study, LED and QTH units may be used to lightcure resin cement when bonding feldspathic ceramic restorations to dentin.

\section{Conclusions}

Based on our results, we concluded that different light-curing units influence the bond strength of ceramic cemented to dentin when photo-cured cement is used, and only after aging (LED > QTH). In addition, there was no difference between the effects of dual- and photo-cured resin-luting agents on the MTBS of the cement used in this study. Thermocycling affected bond strength values.

9. Fan PL, Schumacher RM, Azzolin K, Geary R, Eichmiller FC. Curing-light intensity and depth of cure of resin-based composites tested according to international standards. J Am Dent Assoc. 2002 Apr;133(4):429-34.

10. Santos MJ, Mondelli RF, Francischone CE, Lauris JR, Lima NM. Clinical evaluation of ceramic inlays and onlays made with two systems: a one-year follow-up. J Adhes Dent. 2004 Winter;6(4):333-8.

11. Hofmann N, Papsthart G, Hugo B, Klaiber B. Comparison of photo-activation versus chemical or dual-curing of resinbased luting cements regarding flexural strength, modulus and surface hardness. J Oral Rehabil. 2001 Nov;28(11):1022-8.

12. Della Bona A, Anusavice KJ, Mecholsky JJ Jr. Failure analysis of resin composite bonded to ceramic. Dent Mater. 2003 Dec;19(8):693-9.

13. Akagawa H, Nikaido T, Takada T, Burrow MF, Tagami J. Shear bond strengths to coronal and pulp chamber floor dentin. Am J Dent. 2002 Dec;15(6):383-8.

14. Hofmann N, Hugo B, Klaiber B. Effect of irradiation type (LED or QTH) on photo-activated composite shrinkage strain kinetics, temperature rise and hardness. Eur J Oral Sci. 2002 Dec;110(6):471-9.

15. Rasetto FH, Driscoll CF, Prestipino V, Masri R, von Fraunhofer JA. Light transmission through all-ceramic dental materials: a pilot study. J Prosthet Dent. 2004 May;91(5):441-6.

16. El-Mowafy OM, Rubo MH. Influence of composite inlay/ onlay thickness on hardening of dual-cured resin cements. J Can Dent Assoc. 2000 Mar;66(3):147. 
17. Kamada K, Yoshida K, Atsuta M. Early bond strength durability of bond between a ceramic material and chemically-cured or dual-cured resin luting agent. Am J Dent. 2001 Apr;14(2):85-8.

18. Kuguimiya RN, Alves LB, Seabra FR, Sarmento CF, Santos AJ, Machado CT. Influence of light-curing units and restorative materials on the micro hardness of resin cements. Indian J Dent Res. 2010 Jan-Mar;21(1):49-53.

19. Reges RV, Costa AR, Correr AB, Piva E, Puppin-Rontani RM, Sinhoreti MA, et al. Effect of light-curing units, post-cured time and shade of resin cement on Knoop hardness. Braz Dent J. 2009;20(5):410-3.

20. Santos MJ, Passos SP, Encarnação MO, Santos Jr GC, Bottino MA. Hardening of a dual-cure resin cement using QTH and LED curing units. J Appl Oral Sci. 2010 Mar-Apr;18(2):110-5.

21. Kato H, Matsumura H, Ide T, Atsuta M. Improved bonding of adhesive resin to sintered porcelain with the combination of acid etching and a two-liquid silane conditioner. J Oral Rehabil. 2001 Jan;28(1):102-8.

22. Komori PC, Paula AB, Martin AA, Tango RN, Sinhoreti MA, Correr-Sobrinho L. Effect of light energy density on conversion degree and hardness of dual-cured resin cement. Oper Dent. 2010 Jan-Feb;35(1):120-4.

23. Cerveira GP, Berthold TB, Souto AA, Spohr AM, Marchioro EM. Degree of conversion and hardness of an orthodontic resin cured with a light-emitting diode and a quartz-tungstenhalogen light. Eur J Orthod. 2010 Feb;32(1):83-6.
24. Albino LG, Rodrigues JA, Kawano Y, Cassoni A. Knoop microhardness and FT-Raman evaluation of composite resins: influence of opacity and photoactivation source. Braz Oral Res. 2011 May-Jun;25(3):267-73.

25. Ilie N, Hickel R. Correlation between ceramics translucency and polymerization efficiency through ceramics. Dent Mater. 2008 Jul;24(7):908-14.

26. Feng L, Carvalho R, Suh BI. Insufficient cure under the condition of high irradiance and short irradiation time. Dent Mater. 2009 Mar;25(3):283-9.

27. Akgungor G, Akkayan B, Gaucher H. Influence of ceramic thickness and polymerization mode of a resin luting agent on early bond strength and durability with a lithium disilicatebased ceramic system. J Prosthet Dent. 2005 Sep;94(3):23441.

28. Román-Rodríguez JL, Fons-Font A, Amigó-Borrás V, GranellRuiz M, Busquets-Mataix D, Panadero RA, Solá-Ruiz MF. Bond strength of selected composite resin-cements to zirconium-oxide ceramic. Med Oral Patol Oral Cir Bucal. Forthcoming 2013.

29. Farrokh A, Mohsen M, Soheil S, Nazanin B. Shear bond strength of three self-adhesive resin cements to dentin. Indian J Dent Res. 2012 Mar;23(2):221-5.

30. Castro HL, Passos SP, Zogheib LV, Bona AD. Effect of cement shade and light-curing unit on bond strength of a ceramic cemented to dentin. J Adhes Dent. 2012 Apr;14(2):155-60. 